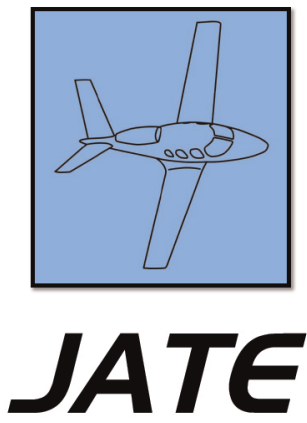

Journal of Aviation Technology and Engineering 3:2 (2014) 14-19

\title{
Stress and Coping as a Function of Experience Level in Collegiate Flight Students
}

\author{
Jennifer Kirschner, John Young, and Richard Fanjoy \\ Purdue University
}

\begin{abstract}
Aviation as an industry requires a high degree of precision at all times. Large amounts of stress have been known to decrease performance to undesirable levels. While stress reactions and the coping skills used after encountering stressful situations differ from person to person, generalities can be made by comparing differences between groups. A large number of pilot applicants receive initial training within a university flight program each year. In order to better understand the perceived stress level and the coping skills used by these students, the current research project administered a perceived stress test and a coping skills inventory to two groups of collegiate pilots: a first-year group $(n=50)$ and a junior/senior group $(n=32)$. Differences were found between the stress levels and coping skills used by this sample population.

High risk industries such as aviation require consistently high levels of performance from employees, regardless of environmental pressures. This is especially the case in flight training, where flight students must adapt to the risks and hazards of the flight environment while learning a new, complex skill set. This can easily leave aviation students feeling overwhelmed. While individual differences play a large role in determining how students respond when placed in stressful situations, generalities can be made using larger groups of students. The current research study measured perceived stress levels and coping skills utilized by two groups of collegiate aviation students drawn from a large Midwestern university.
\end{abstract}

Keywords: aviation psychology, collegiate flight training, stress, stress management, coping

\section{About the Authors}

Jennifer Kirschner is a doctoral candidate at Purdue University. She is a certified flight instructor with experience teaching in collegiate aviation. Her research interests include aviation psychology with an emphasis on stress, burnout, and individual differences in pilots.

John Young is currently a professor in the Department of Aviation Technology at Purdue University. Professor Young's scholarly and research interests include aviation human factors and advanced cockpit training. Professor Young recently served as president of the University Aviation Association, representing over 100 college and university aviation programs.

Richard O. Fanjoy is an Associate Department Head of Aviation Technology at Purdue University. A former military command pilot and instructor/ flight examiner in large jet transport aircraft, he has extensive international flight experience. His research areas include cognitive aspects of flight training and aviation decision making.

Correspondence concerning this article should be sent to jekirsch@purdue.edu. 


\section{Introduction}

Stress can be defined as "any environmental, social, or internal demand which requires the individual to readjust his/her usual behavior patterns" (Thoits, 1995, p. 54). Antecedents of the experience of stress are known as stressors; expectations, demands, and commitments are all examples of stressors (Martinussen \& Hunter, 2010). Because stress involves responses to changing regulatory demands from both the internal and external environment, the experience of stress is dynamic. That is, stress levels can change from day to day or moment to moment (Lazarus, 1991; Thoits, 1995). As soon as the situation demands more resources than are available, stress is experienced. The point at which demand surpasses ability, however, is different for each individual (Martinussen \& Hunter, 2010).

At higher levels, stress can be deleterious, causing reductions in performance (Katz, 1997; Matthews, 2001; Salas, Driskell, \& Hughes, 1996), increased error rates (Martinussen \& Hunter, 2010), and significantly more accidents (Loewenthal, et al., 2000; Young, 2008). Documenting the effects of stress in pilots who fly for hire can be difficult. Some pilots lack awareness about the negative impact stress has on performance. In other instances, the culture of the aviation industry may put pressure on pilots to conceal their stress in fear of having their flight status revoked (Butcher, 2002; Matthews, 2001; Young, 2008).

Aviation professionals commonly experience stress (Matthews, 2001; Larkins, 2010). Captain Jeff Kilmer, executive chairman of the Air Line Pilot Association's Human Performance Structure, was quoted as saying:

Our representatives have seen an uptick across the board in stress-related issues, manifested in medical or professional standards issues and in general malaise...no other industry in the United States has been under more direct stress and pressure since 9/11, and we know that our members are carrying that stress (Burke, 2007, p. 24).

While it may be difficult to accurately report stress levels among pilots, the effects of stress on college students in general have been well documented. This is especially true for students during the first year experience, a period of acclimation to the college environment (Dyson \& Renk, 2006). An increased stress level has been positively correlated with depression in college students (Park, Armeli, \& Tennen, 2004), while many college students meet the criteria for alcohol dependence or abuse (Knight, et al., 2002).

In order to reduce stress, individuals utilize coping skills. Lazarus (1991) defined coping skills as "the cognitive and behavioral efforts a person makes to manage demands that tax or exceed his or her personal resources" (p. 6). The ability to cope with stress can be conceptualized as either a static, unchanging quality or as a skill set that can be learned, but there is a growing trend to view it as the latter (Lazarus, 1991). This implies that more adaptive coping skills can be learned. If one coping strategy is not producing the desired result, another strategy better suited for that situation might be used instead (Aldwin, 2007; Folkman \& Moskowitz, 2004).

Although multiple schemas for categorization exist, some researchers have separated coping strategies into three theoretically derived categories: active (or problem focused), emotion focused, and avoidant (Carver, Scheier, \& Weintraub, 1989; Folkman \& Moskowitz, 2004; Lazarus, 1991; Thoits, 1995; Tennen, Affleck, Armeli, \& Carney, 2000). Active coping strategies are most adaptive when the problem can be solved. They directly attack the source of the stress and attempt to change the situation for the better. Emotional-focused coping, on the other hand, is more effective when the situation cannot be changed and involves articulating feelings about the situation through prayer, venting, or seeking support from friends or family members (Carver, et al., 1989; Cartwright \& Cooper, 2005; Folkman \& Moskowitz, 2004). Avoidant strategies are generally not effective coping strategies and include denying that the stressor exists, mentally disengaging using daydreaming or sleeping, and increasing alcohol/drug use in order to numb the stressful feelings (Folkman \& Moskowitz, 2004; Park et al., 2004).

A coping skills inventory is the most common means of measuring coping ability (Folkman \& Moskowitz, 2004; Parker, Endler, \& Bagby, 1993). Several different types of inventories exist; each lists different facets of coping skills and asks participants to rate the extent to which they use it. While the Ways of Coping Scale is widely used, it was created empirically, using examples thought to describe the range of common coping skills (Parker et al., 1993). The COPE inventory, however, was derived using existing theories about specific types of coping skills in order to not only describe the construct of coping skills, but also stimulate theory development (Carver, Scheier, \& Weintraub, 1989). To decrease completion time, the original 53-question inventory was reduced to a shortened 28-item version (referred to as the Brief-COPE), and uses two questions each to measure the frequency with which individuals report utilizing 14 different coping skills (Carver, 1997). The coping skills measured are self-distraction, active coping, denial, substance abuse, emotional support, behavioral disengagement, venting, instrumental support, positive reframing, blame, planning, humor, acceptance, and religion.

Of the 14 skills, self-distraction measures how often respondents cope with stress by finding other activities in order to "take their mind off" their stressors. The active coping facet asks if participants focus on "doing something 
about the situation" (Carver, 1997, p. 97). Denial relates to refusing to believe how stressful the situation really is. The substance abuse facet asks about drug and alcohol use. Emotional support involves turning to friends or family for comfort and support. Behavioral disengagement measures propensity to stop trying and just give up when stressed. Venting involves talking out negative feelings. Instrumental support, on the other hand, asks if respondents ask for advice and help from others. Positive reframing relates to finding something positive about the situation. Self-blame measures if participants criticize themselves for stressful situations. Planning asks about strategizing and prioritizing to make sure tasks get done. Humor involves joking about the situation. Acceptance asks if participants take responsibility for their actions. Religion relates to finding comfort in religion and/or praying (Lyne \& Roger, 2000).

\section{Research Questions}

This study will answer two questions:

1) Do first-year collegiate flight students have a higher stress level than upper-class flight students?

2) Is the relationship between perceived stress levels and coping skill usage different for first-year collegiate flight students and upper-class flight students?

It was hypothesized that first-year flight students will have a higher stress level than upper-class flight students and that first-year flight students will use different coping skills than upper-class flight students.

\section{Methodology}

In order to examine the stress level and coping skills used by collegiate flight students at one large Midwestern university, a one-time, written survey was distributed in a first-year and a junior/senior level class required for flight majors. A total of 83 students agreed to participate in the survey. Out of the 83 responses, one was removed from the dataset, leaving 82 useable surveys. The 82 surveys included 50 first-year students (47 men and three women, $\mathrm{m}=19$ years) who had or were working towards a private pilot's license and 32 upper-class participants (30 men and two women, $\mathrm{m}=22$ years) who met the requirements for a commercial, multiengine license. One nonaviation major was eliminated from the dataset.

\section{The Research Instrument}

The survey used in this study was designed to capture the stress level of participants over the previous month as well as the coping skills they used. A full-time flight instructor employed at the university and two student pilots not involved in the final study reviewed the survey to verify that students would be able understand the survey instructions.
The survey consisted of demographic information, a stress scale, and a coping skills inventory. Stress was measured by the Perceived Stress Scale (PSS), a widely used measure of the subjective appraisal of one's stress level (Cohen, Kamarck, \& Mermelstein, 1983; Hellhammer, Stone, Hellhammer, \& Broderick, 2010). The PSS contains 10 Likert scale questions that asked participants to rate how stressed they felt over the last month on a 5-point scale, ranging from 0 (never) to 4 (very often). As suggested by Cohen et al. (1983), responses to all items were summed to create a measure of total perceived stress, on a scale from 0 to 40 , over the last month. Stress coping skills were measured by a coping skills inventory referred to as the Brief-COPE (Carver, 1997). The Brief-COPE consists of 28 Likert scale questions that ask how often participants had used one of 14 different coping skills over the last month. Responses ranged from 1 (I do not usually do this) to 5 (I do this a lot). See Table 1 for a summary of the descriptive statistics and psychometric properties for each of the survey scales. There are 14 coping skills included in the survey, but only those with reliabilities over 0.6 were included in the current study (Cook, Thompson, \& Coca-Lyle, 2012).

\section{Results}

\section{Research Question One}

In order to test the hypothesis that first-year students would report a higher stress level than upper-class students, the mean perceived stress level for both groups was analyzed. The mean level of stress for the first-year and upper-class groups were $15.58(\mathrm{SD}=5.92)$ and $12.94(\mathrm{SD}$ $=5.01$ ), respectively, on a 40-point scale. Norms for a group of 648 18-29 year olds established the average stress level at 15.3 (SD = 6.6 [Cohen et al., 1983]). There was no significant difference between the norm and the group of freshmen, $\mathrm{t}(49)=0.34, \mathrm{p}=0.739$, but the upperclassmen scored lower than the norm, $\mathrm{t}(31)=-2.67, \mathrm{p}=0.012$.

A one-way ANOVA was performed on the mean stress levels to determine if there was a statistically significant difference between the two groups. The null hypothesis of no difference between the groups was rejected, $\mathrm{F}=4.37$, $\mathrm{p}=.040$. Therefore, Hypothesis 1 was confirmed. The upperclassmen reported their subjective experience of stress to be lower than the first-year students.

\section{Research Question Two}

To test the hypothesis that the relationship between perceived stress levels and coping skill usage would be different for first-year collegiate flight students and upperclass flight students, a Pearson correlation matrix was constructed. Two correlation matrices were constructed using SPSS 21, one for the first-year students and another for the upper-class students (see Table 2 for a summary). 
Table 1

Descriptive statistics and psychometric properties for study instruments.

\begin{tabular}{|c|c|c|c|c|c|c|c|}
\hline \multirow[b]{2}{*}{ Variable $(n=82)$} & \multirow[b]{2}{*}{$M$} & \multirow[b]{2}{*}{$S D$} & \multirow[b]{2}{*}{$\alpha$} & \multirow[b]{2}{*}{ No. of Items } & \multicolumn{2}{|c|}{ Range } & \multirow[b]{2}{*}{ Skew } \\
\hline & & & & & Potential & Actual & \\
\hline Stress & 14.55 & 5.7 & 0.812 & 10 & $0-40$ & $0-30$ & 0.39 \\
\hline \multicolumn{8}{|l|}{ Coping } \\
\hline Substance abuse & 2.74 & 1.15 & 0.885 & 2 & $2-6$ & $2-6$ & 1.36 \\
\hline Emotional support & 4.67 & 1.7 & 0.839 & 2 & $2-6$ & $2-8$ & 0.25 \\
\hline Instrumental support & 5.24 & 1.71 & 0.839 & 2 & $2-6$ & $2-8$ & -0.23 \\
\hline Positive reframing & 5.65 & 1.38 & 0.709 & 2 & $2-6$ & $2-8$ & -0.23 \\
\hline Self-blame & 4.45 & 1.57 & 0.687 & 2 & $2-6$ & $2-8$ & $\begin{array}{r}-0.25 \\
0.48\end{array}$ \\
\hline Planning & 6.41 & 1.24 & 0.700 & 2 & $2-6$ & $4-8$ & -0.36 \\
\hline Humor & 5.07 & 1.75 & 0.814 & 2 & $2-6$ & $2-8$ & -0.09 \\
\hline Religion & 4.01 & 2.12 & 0.916 & 2 & $2-6$ & $2-8$ & 0.61 \\
\hline
\end{tabular}

For first-year students, perceived stress level was correlated with self-blame, $\mathrm{r}(50)=0.425, \mathrm{p}=0.002$, and humor, $r(50)=-0.284, p=0.046$. First-year students who were less stressed blamed themselves less for unfavorable situations and were more able to make light of their problems. In contrast, perceived stress level for upperclassmen was correlated with instrumental support, $\mathrm{r}(32)=$ $-0.414, \mathrm{p}=0.018$, positive reframing, $\mathrm{r}(32)=-0.370, \mathrm{p}=$ 0.037 , and self-blame, $\mathrm{r}(32)=-0.374, \mathrm{p}=0.035$. Upperclassmen that were less stressed relied more on help and advice from friends, were more able to see their situation in a positive way, and blamed themselves less for their problems.

In order to examine these relationships in better detail, scatterplots were constructed to verify that there was a linear relationship between stress and the coping skills identified (Field, 2013). A linear regression analysis was then used to confirm that self-blame and humor explained a significant proportion of variance in perceived stress level for first-year students, $\mathrm{R} 2=0.253, \mathrm{~F}(2,47)=7.95, \mathrm{p}=$ 0.001. Lastly, a linear regression analysis was used to confirm that instrumental support, positive reframing, and self-blame explained a significant proportion of variance in perceived stress level for upperclassmen, R2 $=0.292, \mathrm{~F}(3$, 28) $=3.85, \mathrm{p}=0.020$.

\section{Discussion}

Due to the dynamic nature of the flight environment, aviation requires consistently high levels of performance.
This is especially the case in flight training contexts where one must face not only the risks and hazards of the flight environment, but also the pressure of learning a new, complex skill set. While individual differences play a large role in determining how students respond when placed in stressful situations, generalities can be made using larger groups of students. This study, in particular, measured perceived stress levels and coping skills utilized by two groups of collegiate aviation students drawn from a large Midwestern university.

Two main conclusions are suggested by the current research study: (1) upper-class flight students report less perceived stress than first-year students, and (2) upper-class flight students used different coping skills to deal with their stress level than first-year students.

The first year at college is a particularly stressful time for students, as they undergo many changes; anxiety, depression, and high attrition rates are common (Rayle \& Chung, 2007). The decrease in stress for the upper-class group could be due to students with higher-stress levels selfselecting out of the aviation program after their first year or students learning how to better cope with their stress level as they mature in college. Another possible explanation could be that increased exposure to the stressors specific to flight training decreases sensitivity to them, which, in turn, lowers stress level over time. The continued exposure to stressful situations such as flight training may increase confidence in one's ability to handle those stressors.

Coping skills could have changed in the upper-class group as students self-selected out of the program, matured

Table 2

Bivariate correlations among survey subscales.

\begin{tabular}{|c|c|c|c|c|c|c|c|c|}
\hline & Substance abuse & Emotional support & Instrumental support & Positive reframing & Self-blame & Plan & Humor & Religion \\
\hline $\begin{array}{l}\text { Stress-first year } \\
\quad(n=50)\end{array}$ & 0.236 & 0.243 & 0.183 & -0.111 & $0.425^{* *}$ & -0.075 & $-0.284 *$ & 0.048 \\
\hline $\begin{array}{l}\text { Stress-upper class } \\
\quad(n=32)\end{array}$ & -0.120 & -0.161 & $-0.414^{*}$ & $-0.370^{*}$ & $0.374^{*}$ & -0.279 & -0.176 & -0.053 \\
\hline
\end{tabular}


over time, or learned more adaptive coping skills. Refusing to blame themselves for difficult situations and using humor are skills that serve first-year students well. An unfamiliar environment and a challenging curriculum can take students out of their comfort zone and leave them feeling overwhelmed. Upper-class students, however, focused more on reaching out to others for help, reframing problems in a positive light, and not blaming themselves. This could be due to an increased focus on participating in the multipilot operations in line-oriented flight training (LOFT) scenarios found in junior- and senior-level courses. Upper-level classes in crew resource management (CRM) and human factors expose students to the benefits of operating in a crew situation and incorporating others in their decision-making process.

\section{Limitations of the Study}

The correlational nature of the study means that it cannot prove cause and effect, only point to significant relationships. Several other factors could have influenced the outcomes found during this study. The two groups used in this study were chosen for their different levels of flight training, but were inherently different at the start of the study for several other reasons. Students who volunteered to participate in the study could have different levels of stress and cope differently than students unwilling to participate. Because not all enrolled students took part in the study, the results provide only an estimation of how the larger student population functions. Also, the assumption cannot be made that more experienced students decreased their stress levels or improved their coping styles over time. One possibility is that students with higher stress levels might have self-selected out of the aviation program instead of continuing on. These effects cannot be separated out due to the nonrandomization of participants. Therefore, although there is a correlation between flight class and the coping skills used, causation cannot be assumed.

\section{Future Research}

Additional research is needed to contrast these changes with normal maturity changes occurring in nonaviation students. A four by four design would allow researchers to better separate the changes in coping mechanism associated with an intensive flight-focused course of study. Another avenue for future research is longitudinal, "daily process" approaches to measuring how stress level and coping styles change for each individual over time. A daily process approach to measuring coping skill usage would involve either a diary in which participants record their stress level and the coping skills they use on a daily/weekly basis, or a personal digital assistant (PDA) that queries participants about their stress level and coping skill usage at randomized points throughout the day. This would document how stress level and coping skills use changed over time, instead of how they vary between groups of people.

\section{References}

Aldwin, C. M. (2007). Stress, coping, and development: An integrative perspective (2nd ed.). New York, NY: Guilford.

Burke, S. (2007). When your mental state cries "mayday" your union stands with you. Journal of the Air Line Pilots Association, 76(7), 2427. Retrieved from https://www.alpa.org/portals/alpa/magazine/2007/ Aug2007_MentalState.pdf

Butcher, J. N. (2002). Assessing pilots with the "wrong stuff": A call for research on emotional health factors in commercial aviation. International Journal of Selection and Assessment, 10, 168-183. Retrieved from http://papers.ssrn.com/sol3/papers.cfm?abstract_ id $=312700$

Cartwright, S., \& Cooper, C. (2005). Individually targeted interventions. In J. Barling, E. K. Kelloway, \& M. R. Frone (Eds.), Handbook of work stress (pp. 607-622). Thousand Oaks, CA: SAGE Publications, Inc. http://dx.doi.org/10.4135/9781412975995.n26

Carver, C. S. (1997). You want to measure coping but your protocol's too long: Consider the Brief COPE. International Journal of Behavioral Medicine, 4(1), 92-100. http://dx.doi.org/10.1207/s15327558 ijbm0401_6

Carver, C. S., Scheier, M. F., \& Weintraub, J. K. (1989). Assessing coping strategies: A theoretically based approach. Journal of Personality and Social Psychology, 56(2), 267-283. http://dx.doi.org/10.1207/ s15327558ijbm0401_6

Cohen, S., Kamarck, T., \& Mermelstein, R. (1983). A global measure of perceived stress. Journal of Health and Social Behavior, 24(4), 385396. http://dx.doi.org/10.2307/2136404

Cook, S. W., Thompson, C. L., \& Coca-Lyle, V. A. (2012). The psychology of stress and coping. In K. L. Goodheart, J. R. Clopton, \& J. J. Robert-McComb (Eds.), Eating disorders in women and children: Prevention, stress management, and treatment (pp. 125-141). Boca Raton, FL: CRC Press. http://dx.doi.org/10.1201/b11381-10

Dyson, R., \& Renk, K. (2006). Freshman adaptation to university life: Depressive symptoms, stress, and coping. Journal of Clinical Psychology, 62(10), 1231-1244. http://dx.doi.org/10.1002/jclp.20295

Field, A. P. (2013). Discovering statistics using IBM SPSS Statistics: And sex and drugs and rock ' $n$ ' roll (4th ed.). London, England: SAGE Publications Ltd. Retrieved from http://www.sagepub.com/upm-data/ 52063_00_Field_4e_SPSS_Prelims.pdf

Folkman, S., \& Moskowitz, J. T. (2004). Coping: Pitfalls and promise. Annual Review of Psychology, 55, 745-774. http://dx.doi.org/10.1146/ annurev.psych.55.090902.141456

Hellhammer, D. H., Stone, A. A., Hellhammer, J., \& Broderick, J. (2010). Measuring stress. In G. F. Koob, M. Le Moal, \& R. F. Thompson (Eds.), Encyclopedia of behavioral neuroscience (Vol. 2) (pp. 186191). Oxford, England: Elsevier. http://dx.doi.org/10.1016/B978-0-08045396-5.00188-3

Katz, L. C. (1997). Stress, coping, belief systems, and symptoms (USAARL Report No. 97-37). Fort Rucker, AL: U.S. Army Aeromedical Research Center.

Knight, J. R., Wechsler, H., Kuo, M., Seibring, M., Weitzman, E. R., \& Schuckit, M. A. (2002). Alcohol abuse and dependence among U.S. college students. Journal of Studies on Alcohol, 63(3), 263-270. Retrieved from http://www.jsad.com/jsad/article/Alcohol_Abuse_and_ Dependence_among_US_College_Students/1284.html

Larkins, A. (2010). Stress and the war on error. Mobility Forum: The Journal of the Air Mobility Command's Magazine, 19(2), 4-7.

Lazarus, R. S. (1991). Psychological stress in the workplace. In P. L. Perrewe (Ed.), Handbook on job stress [special issue], Journal of Social Behavior and Personality, 6, 1-13.

Loewenthal, K. M., Eysenck, M., Harris, D., Lubitsh, G., Gorton, T., \& Bicknell, H. (2000). Stress, distress and air traffic incidents: Job 
dysfunction and distress in airline pilots in relation to contextuallyassessed stress. Stress Medicine, 16(3), 179-183. http://dx.doi.org/10. 1002/(SICI)1099-1700(200004)16:3\%3C179::AID-SMI851\%3E3.0. $\mathrm{CO} ; 2-4$

Lyne, K., \& Roger, D. (2000). A psychometric re-assessment of the COPE questionnaire. Personality and Individual Differences, 29(2), 321-335. http://dx.doi.org/10.1016/S0191-8869(99)00196-8

Matthews, G. (2001). A transactional model of driver stress. In P. A. Hancock \& P. A. Desmond (Eds.), Stress, workload, and fatigue (pp. 133-163). Mahwah, NJ: Lawrence Erlbaum Associates.

Martinussen, M., \& Hunter, D. (2010). Aviation psychology and human factors. Boca Raton, FL: CRC Press.

Park, C. L., Armeli, S., \& Tennen, H. (2004). The daily stress and coping process and alcohol use among college students. Journal of Studies on Alcohol, 65(1), 126-135. Retrieved from http://www.jsad.com/jsad/ article/The_Daily_Stress_and_Coping_Process_and_Alcohol_Use_ among_College_Students/1117.html

Parker, J. D., Endler, N. S., \& Bagby, R. M. (1993). If it changes, it might be unstable: Examining the factor structure of the Ways of Coping
Questionnaire. Psychological Assessment, 5(3), 361-368. http://dx.doi. org/10.1037/1040-3590.5.3.361

Rayle, A. D., \& Chung, K.-Y. (2007). Revisiting first-year college students' mattering: Social support, academic stress, and the mattering experience. Journal of College Retention, 9(1), 21-37. http://dx.doi. org/10.2190/X126-5606-4G36-8132

Salas, E., Driskell, J. E., \& Hughes, S. (1996). Introduction: The study of stress and human performance. In J. E. Driskell \& E. Salas (Eds.), Stress and human performance (pp. 1-45). Mahwah, NJ: Lawrence Erlbaum Associates.

Thoits, P. A. (1995). Stress, coping, and social support processes: Where are we? What next? Journal of Health and Social Behavior, 35 (Extra Issue), 53-79. http://dx.doi.org/10.2307/2626957

Tennen, H., Affleck, G., Armeli, S., \& Carney, M. A. (2000). A daily process approach to coping: Linking theory, research, and practice. American Psychologist, 55(6), 626-636. http://dx.doi.org/10.1037/ 0003-066X.55.6.626

Young, J. (2008). The effects of life-stress on pilot performance (NASA/ TM-2008-215375). Moffett Field, CA: Ames Research Center. 